if she has not seen the 40 patients in a day that is required by her 'plan'.

Attempts to pursue academic activity, in spite of official repression, also serve to improve morale as well as helping refusenik physicians and scientists keep up to date. Medical seminars had been organised regularly by Dr Goldfarb but since his departure they have become more difficult to arrange. One of the authors (PR) was asked to speak to a group of refusenik physicians. This seminar took place in the living room of a refusenik's small flat in Moscow. A very old slide projector was found and a lecture given on the role of gastric function in satiety. The discussion was lively and compared favourable with comments and questions after a similar talk given at a conference in New York, one month before. By means of such seminars the medical refuseniks, prohibited from pursuing their own research interests, are able to have some contact with medical researchers. An abstract of the seminar given in Moscow has been submitted to a new journal dedicated to reporting the academic activities, many clandestine, that are organised by the refuseniks. ${ }^{4}$

\section{Discussion}

Little previous information has emerged on the health of people held in the Soviet Union awaiting exit visas. We found indications that this form of political repression is associated with both psychiatric and physical morbidity. However, our information is anecdotal and there is a need for a more formal assessment of the epidemiology of the problem. Our impression was that illness on receiving a refusal was common, and that support provided by the very close-knit community was an important way of coping with persecution and ostracism that often followed a visa application. A study of the extent and nature of this morbidity would require a comprehensive survey, perhaps organised by the refusenik physicians themselves.

Soviet refusenik physicians are often subjected to disruption of their professional development as soon as they apply to emigrate. They usually lose their jobs, and researchers are denied the opportunity to continue their studies or publish work already completed. This treatment cannot be construed as other than punishment for submitting a visa application, the refusal of which prevents these doctors from leaving the country to pursue their research elsewhere. This abuse continues during the present era of supposed liberalisation. It is our view that treatment of medical refuseniks might improve if colleagues in the West expressed their disapproval and concern to the Soviet medical establishment.

\section{REFERENCES}

'GoLDFARB, L. (1986) Address to workshop 'The psychology of being a refusenik', Oxford, 23 November 1986.

${ }^{2}$ Robinson, P. H. \& Berger, M. (1986) Soviet physicians denied exist visas. Lancet, ii, 690.

${ }^{3}$ Brown, G. W., Bhrolchain, M. N. \& Harris, T. (1975) Social class and psychiatric disturbance among women in an urban population. Sociology, 9, 225-254.

${ }^{4}$ RoBrnson, P. H. Gastric function and satiety. Journal of the Academic Proceedings of Soviet Jewry. (Submitted).

\title{
The Gower's Prize
}

The Gower's Prize is awarded biennially by the council of the International League Against Epilepsy (British Branch) for the best dissertation on any topic related to epilepsy of not more than $\mathbf{5 0 0 0}$ words presented in English. Entries can be accepted from anywhere in the world providing they are in English. There are three sections to the Gower's Prize:

1. The Young Physicians Prize of $£ 250$, limited to young qualified doctors under the age of 35 at the time they submit their dissertation.

2. The Medical Students Prize of $£ 100$ each. One for a dissertation on epilepsy, the other for the best case history of a patient or patients with epilepsy personally seen by the medical student. This part of the competition is open to bona fide medical students of any university and includes those students qualifying in the years 1987-88
3. The Health Professionals Prize of $£ 100$, awarded for the best dissertation submitted by any bona fide health professional, trainee health professional in any discipline related to epilepsy.

In all three categories runner-up prizes may be awarded if of sufficient merit. Typed entries should be submitted by 1 June 1988. Details of the entrant's name and address and place of work should be submitted separately with the entry so that the judges of the competition will not be aware of where the entries have come from. Prizes will only be awarded if they are deemed to be of sufficient merit and prize winners will be invited to the British/Danish/Dutch biennial symposium on epilepsy to be held near Amsterdam in September 1988.

Entries should be sent to Dr T. A. Betts, Neurophysiology Unit, Aston University, Aston Triangle, Birmingham, B4 7ET. 